\title{
Influence of Asthma on the Longitudinal Trajectories of Cigarette Use Behaviors From Adolescence to Adulthood Using Latent Growth Curve Models
}

\section{Jisuk Bae}

Department of Preventive Medicine, Catholic University of Daegu School of Medicine, Daegu, Korea

Objectives: While epidemiologic research indicates that the prevalence of risk-taking behaviors including cigarette smoking among young people with asthma is substantial, the longitudinal patterns of cigarette smoking in this vulnerable population have received little attention. The aim of this study was to evaluate differences in the longitudinal trajectories of cigarette use behaviors from adolescence to adulthood between young people with and without asthma.

Methods: Data from the National Longitudinal Study of Adolescent to Adult Health (Add Health) during the years 1994 to 1995 (Wave I, adolescence), 2001 to 2002 (Wave III, young adulthood), and 2007 to 2008 (Wave IV, adulthood) were analyzed (n=12 244). Latent growth curve models were used to examine the longitudinal trajectories of cigarette use behaviors during the transition to adulthood according to asthma status.

Results: Regardless of asthma status, the trajectory means of cigarette use behaviors were found to increase, and then slightly decrease from adolescence to adulthood. In total participants, there were no statistically significant differences in initial levels and changes in cigarette use behaviors according to asthma status. However, in select sex and race subgroups (i.e., females and nonwhites), former asthmatics showed greater escalation in cigarette use behaviors than did non-asthmatics or current asthmatics.

Conclusions: This study indicated that the changing patterns of cigarette use behaviors during the transition to adulthood among young people with asthma are comparable to or even more drastic than those among young people without asthma.

Key words: Adolescent, Asthma, Health behavior, Latent growth modeling, Smoking, Young adult

\section{INTRODUCTION}

Asthma is one of the most common chronic respiratory diseases worldwide. Although recent international studies have

Received: December 8, 2014 Accepted: March 17, 2015

Corresponding author: Jisuk Bae, MD, PhD

33 Duryugongwon-ro 17-gil, Nam-gu, Daegu, 705-718, Korea

Tel: +82-53-650-3190, Fax: +82-53-654-3881

E-mail: jialove@cu.ac.kr

This is an Open Access article distributed under the terms of the Creative Commons Attribution Non-Commercial License (http://creativecommons.org/licenses/bync/3.0/) which permits unrestricted non-commercial use, distribution, and reproduction in any medium, provided the original work is properly cited. shown geographical variations in the prevalence of asthma, the prevalence of the disease has been increasing markedly in recent decades especially in developed countries, and the global burden of the disease to governments, health care systems, families, and patients has become substantial [1]. In the US, national data from the Centers for Disease Control and Prevention National Asthma Control Program showed that 18.7 million adults and 7 million children had asthma in 2010. In 2009, the numbers of asthma-related doctor visits and emergency department visits were 8.9 million and 1.9 million, respectively. Asthma was the cause of 14.2 million missed days of work and 10.5 million missed days of school in 2008 [2]. In the Republic of Korea (hereafter Korea), national survey data showed that the 
prevalence of physician-diagnosed asthma was 9.2\% among middle and high school students in 2014 [3]. Of those with physician-diagnosed asthma, 21.3\% missed school in 2014 due to issues related to the disease [3].

Notwithstanding the fact that cigarette smoking is related to the exacerbation of asthma and the occurrence of asthma symptoms, previous studies have shown that the prevalence of cigarette smoking among asthmatic adolescents is similar to or even higher than that among non-asthmatic adolescents $[4,5]$. Asthma, especially in childhood and adolescence, is known to be related to psychosocial impairment and behavioral maladjustment [6-8]. Several previous studies demonstrated that asthmatic children and adolescents are more likely than their healthy peers to manifest anxious and depressive symptoms and engage in health risk behaviors such as cigarette smoking, alcohol drinking, and illicit drug use [7-9]. In addition, some evidence has suggested that these psychosocial and behavioral problems among asthmatics are related to non-adherence to medications, poor treatment outcomes, and death [9]. Although there is less research on the prevalence of cigarette smoking among asthmatic adults, previous studies have reported that cigarette smoking in this group is common, with the prevalence rate similar to or even higher than that in the general population $[10,11]$.

In contrast to a growing body of evidence on pervasive cigarette use behaviors among asthmatic youth with various underlying reasons for cigarette smoking $[12,13]$, a paucity of research exists on the longitudinal patterns of cigarette use behaviors in this chronically ill population. Sparse evidence has been derived from studies using data from the National Longitudinal Study of Adolescent to Adult Health (Add Health). Tercyak [14] reported that adolescents with and without asthma were equally likely to experience progression in their cigarette use behaviors during a 1-year follow-up period; and exposure to friends who smoked was a consistent and powerful social risk factor for smoking progression among asthmatic adolescents. Dowdell et al. [15] found that the smoking rate among asthmatic adolescents increased with age until young adulthood, and this rate was equal to or even higher than that among non-asthmatics. As emphasized in the developmental psychopathology theory [16], the changing patterns of cigarette use behaviors across developmental stages, such as adolescence, young adulthood, and adulthood, need to be elucidated to identify young people with asthma at higher risk for cigarette smoking and implement smoking prevention and cessation programs that address their special needs. As a study expanding on the data analysis of Add Health, the present study aimed to evaluate differences in the longitudinal trajectories of cigarette use behaviors from adolescence to adulthood between young people with and without asthma.

\section{METHODS}

\section{Study Population}

Add Health is a nationally representative panel study of youth in the US. As described previously in detail $[17,18]$, Add Health includes data from an in-school survey during the years 1994 -1995 and multiple in-home interviews during the years 19941995 (Wave I), 1996 (Wave II), 2001-2002 (Wave III), and 20072008 (Wave IV). The in-school survey was conducted in a sample of 80 high schools and 52 feeder schools, which were selected by systematic sampling methods and implicit stratification to be representative of all schools in the US with respect to the region of country, degree of urbanicity, size, type of school, and ethnicity of the students. The first in-home interview was completed among 20745 adolescents in grades 7 to 12 from the pool of participants in the in-school survey. After a 1-year interval, 14 738 adolescents, who were 8 to 12 graders, were interviewed at home. The Wave III in-home survey was conducted among 15197 young adults aged 18 to 26 years from the Wave I inhome survey participants. The Wave IV in-home survey was conducted among 15701 adults from the Wave I in-home survey participants, now aged 24 to 32 years. In the present study, three data time points from Add Health (i.e., Wave I [adolescence], Wave III [young adulthood], and Wave IV [adulthood]) were analyzed to estimate the longitudinal trajectories of cigarette use behaviors. The sample was restricted to participants interviewed at Wave I, Wave III, and Wave IV with valid measures of data at each time point $(n=12244)$.

\section{Asthma Status}

Asthma status was classified into three groups using the Wave III data: current asthmatics (those who had been diagnosed with asthma, and had been treated for asthma during the past 12 months; $n=630$ ), former asthmatics (those who had been diagnosed with asthma, but had not been treated for asthma during the past 12 months; $n=1439$ ), and non-asthmatics (those who had never been diagnosed with asthma; $\mathrm{n}=10$ 175).

\section{Cigarette Use Behaviors}

Cigarette use behaviors at each time point were assessed by 
considering smoking frequency and quantity. Smoking frequency was recorded as a score from one to five according to the number of days that participants smoked cigarettes during the past 30 days, which ranged from never to everyday. Smoking quantity was recorded as a score from one to five based on the number of cigarettes smoked per day on the days smoked during the past 30 days, which ranged from 0 to $\geq 40$. The smoking score was calculated as the sum of the smoking frequency and quantity scores, which ranged from two to 10 . Admittedly, the smoking score used in the present study was arbitrarily defined, given the absence of established validity for the use of such an assessment approach [19].

\section{Statistical Analysis}

The distributions of selected characteristics were summarized as frequencies and weighted percentages. Differences in proportions across multiple time points were assessed using chisquare tests. The data were subjected to latent growth modeling using the AMOS 20.0 statistical software (IBM Corp., Armonk, NY, USA). Initial levels and changes in cigarette use behaviors from adolescence to adulthood were determined using a linear change model (Wave I estimate, 0 ; and Wave III estimate, 1) with the final time point (Wave IV) freely estimated to improve the model fit. The model fit was evaluated using the root mean squared error of approximation (RMSEA) with both $0.05 \leq$ RMSEA $<0.10$ (a reasonable fit) and RMSEA $<0.05$ (a good fit) considered acceptable in conjunction with the comparative fit index (CFI) with $>0.90$ considered acceptable [20]. Separate models were tested for each asthma subgroup. In order to test differences in the longitudinal trajectories of cigarette use behaviors according to asthma status, the categorical variable of asthma status was included as a covariate in the models. All tests were two-sided with $p$-value $<0.05$ considered statistically significant. This study was performed in accordance with the guidelines of the Declaration of Helsinki and approved by the institutional review boards of Daegu Catholic University Medical Center in Korea.

\section{RESULTS}

Of 12244 study participants, the weighted percentages of those who smoked on 20 or more days during the past 30 days were $12.1 \%, 29.0 \%$, and $27.7 \%$ at Wave I, III, and IV, respectively. Those who smoked $\geq 10$ cigarettes per day during the past 30 days comprised $6.9 \%, 20.7 \%$, and $20.2 \%$ of the study partici- pants at Wave I, III, and IV, respectively. There were statistically significant differences in the distributions of cigarette use behaviors across the three time points (Table 1). Differences in initial levels and changes in cigarette use behaviors from adolescence to adulthood according to asthma status are presented in Table 2. The values of RMSEA and CFI were acceptable, reflecting a good or reasonable model fit to the data; however, the model for current asthmatics who were non-whites had an RMSEA $\geq 0.10$, reflecting a poor fit. For all models, statistically significant individual differences in both initial levels and changes in cigarette use behaviors were observed.

Regardless of asthma status, the trajectory means of cigarette use behaviors were found to increase, and then slightly decrease during the transition to adulthood (Wave IV estimate, 0.973 for non-asthmatics; 0.940 for former asthmatics; and 0.975 for current asthmatics). In the subgroup analyses by sex and race, this pattern of cigarette smoking was observed among former asthmatics in all of the subgroups (Wave IV estimate, 0.977 for males; 0.892 for females; 0.904 for whites; and 0.991 for non-whites). In total participants, there were no statistically significant differences in initial levels and changes in cigarette use behaviors according to asthma status. However, in select sex and race groups (i.e., females and non-whites), former asthmatics showed greater escalation in cigarette use behaviors from adolescence to adulthood than did non-asthmatics or current asthmatics (Table 2).

\section{DISCUSSION}

This study presents the changing patterns of cigarette use behaviors across important developmental stages (i.e., adolescence, young adulthood, and adulthood) according to asthma status. The longitudinal findings showed that the rate of cigarette smoking increased overall from adolescence to young adulthood. After this stage, however, cigarette use behaviors became relatively stable or declined by adulthood. One conceivable explanation for this finding is that adverse health consequences caused by cigarette smoking at a young age may have deterred these individuals from persistent cigarette smoking through adulthood; this might be especially true among young people with asthma $[21,22]$. Given that cigarette smoking can increase the severity and occurrence of asthma symptoms such as coughing, wheezing, and shortness of breath, young people with asthma are considered more susceptible to the adverse health effects of cigarette smoking than their healthy peers are. A clinical review on smoking and asthma reported that cigarette 
Table 1. Characteristics of the study participants from the National Longitudinal Study of Adolescent Health (Wave I, 1994-1995; Wave III, 2001-2002; and Wave IV, 2007-2008; $\mathrm{n}=12$ 244)

\begin{tabular}{|c|c|c|c|c|}
\hline Characteristic & $\begin{array}{c}\text { Wave I } \\
\text { (adolescence) }\end{array}$ & $\begin{array}{c}\text { Wave III } \\
\text { (young adulthood) }\end{array}$ & $\begin{array}{c}\text { Wave IV } \\
\text { (adulthood) }\end{array}$ & $p$-value ${ }^{1}$ \\
\hline \multicolumn{5}{|l|}{ Birth year } \\
\hline 1982-1983 & - & $1078(12.1)$ & - & \\
\hline $1980-1981$ & - & $3559(38.2)$ & - & \\
\hline 1978-1979 & - & $4678(37.5)$ & - & \\
\hline 1976-1977 & - & $2827(11.8)$ & - & \\
\hline 1974-1975 & - & $102(0.4)$ & - & \\
\hline \multicolumn{5}{|l|}{ Sex } \\
\hline Male & - & $5501(49.3)$ & - & \\
\hline Female & - & $6743(50.7)$ & - & \\
\hline \multicolumn{5}{|l|}{ Race/ethnicity } \\
\hline Non-Hispanic white & - & $6901(69.6)$ & - & \\
\hline Non-Hispanic black & - & $2548(14.3)$ & - & \\
\hline Hispanic & - & $1903(11.8)$ & - & \\
\hline Asian/Pacific Islander & - & $782(3.4)$ & - & \\
\hline Native American & - & $110(0.9)$ & - & \\
\hline Frequency of cigarette use (during the past $30 \mathrm{~d}$ ) & & & & $<0.001$ \\
\hline$<20 d$ & 10762 (87.9) & $9160(71.0)$ & $9325(72.3)$ & \\
\hline$\geq 20 \mathrm{~d}$ & $1482(12.1)$ & $3084(29.0)$ & $2919(27.7)$ & \\
\hline Quantity of cigarette use (during the past $30 \mathrm{~d}$ ) & & & & $<0.001$ \\
\hline$<10$ cigarettes $/ \mathrm{d}$ & $11440(93.1)$ & $10116(79.3)$ & $10193(79.8)$ & \\
\hline$\geq 10$ cigarettes/d & $804(6.9)$ & $2128(20.7)$ & $2051(20.2)$ & \\
\hline Frequency of alcohol drinking (during the past $12 \mathrm{mo}$ ) & & & & $<0.001$ \\
\hline None & $6505(55.5)$ & $3239(25.5)$ & $3344(25.1)$ & \\
\hline Once a month or less & $3708(29.4)$ & $3560(28.1)$ & $3221(25.9)$ & \\
\hline 2 or $3 \mathrm{~d} / \mathrm{mo}$ & $956(7.3)$ & $2063(15.8)$ & $2030(16.9)$ & \\
\hline 1 or $2 \mathrm{~d} / \mathrm{wk}$ & $723(5.1)$ & $2263(20.0)$ & $2322(20.4)$ & \\
\hline 3 to $5 \mathrm{~d} / \mathrm{wk}$ & $255(1.8)$ & $864(8.2)$ & $1015(9.2)$ & \\
\hline Everyday & $97(0.8)$ & $255(2.4)$ & 312 (2.6) & \\
\hline
\end{tabular}

Values are presented as number (weighted \%).

${ }^{1}$ Calculated by chi-square tests.

smoking and exposure to secondhand smoke in asthmatics led to poor patient outcomes and reduced the effectiveness of steroid therapy, possibly via various biologic mechanisms such as toxins direct to the bronchial epithelium causing oxidative damage, the release of proinflammatory mediators and cytokines, and increased epithelial permeability [22]. Nevertheless, the present study demonstrated that the changing patterns of cigarette use behaviors during the transition to adulthood among young people with asthma were not different from those among young people without asthma, indicative of even more escalating patterns in select sex and race subgroups.

Adolescence and young adulthood are periods in which a large number of young people are likely to engage in health risk behaviors including cigarette smoking. Many psychosocial, behavioral, and environmental factors have been identified as being associated with cigarette use behaviors among young people $[12,23]$. The changing patterns of cigarette smoking over time have also been evaluated in some longitudinal studies. With the lack of consistency across studies, some distinct developmental trajectory groups (e.g., non/experimental smokers, occasional/maturing out smokers, and heavy/regular smokers) have been identified $[19,21,24]$. However, there is limited knowledge of how a variety of factors influences the longitudinal patterns of cigarette smoking among young people with asthma. There has been a body of literature on risk-taking behaviors among young people with chronic illness such as asth- 
Table 2. Differences in initial levels (intercepts) and changes (slopes) in cigarette use behaviors ${ }^{1}$ according to asthma status ${ }^{2}$ from the National Longitudinal Study of Adolescent Health (Wave I, 1994-1995; Wave III, 2001-2002; and Wave IV, 2007-2008)

\begin{tabular}{|c|c|c|c|c|c|c|c|c|c|}
\hline & \multirow{2}{*}{$\mathbf{n}$} & \multirow{2}{*}{ Intercept $^{3}$} & \multirow{2}{*}{ Slope $^{3}$} & \multirow{2}{*}{ Wave IV estimate } & \multicolumn{3}{|c|}{ Trajectory mean } & \multirow{2}{*}{ RMSEA } & \multirow{2}{*}{ CFI } \\
\hline & & & & & Wave I & Wave III & Wave IV & & \\
\hline \multicolumn{10}{|l|}{ Total participants } \\
\hline Former asthmatics & 1439 & 3.000 & 0.817 & 0.940 & 3.000 & 3.817 & 3.768 & 0.042 & 0.996 \\
\hline Current asthmatics & 630 & 2.902 & 0.720 & 0.975 & 2.902 & 3.622 & 3.604 & 0.050 & 0.994 \\
\hline Non-asthmatics & 4634 & 2.990 & 0.892 & 1.007 & 2.990 & 3.883 & 3.889 & 0.051 & 0.994 \\
\hline Former asthmatics & 667 & 2.951 & 0.977 & 0.977 & 2.951 & 3.928 & 3.906 & 0.061 & 0.991 \\
\hline Current asthmatics & 200 & 2.740 & 0.985 & 0.874 & 2.740 & 3.725 & 3.600 & 0.070 & 0.987 \\
\hline$p$-value ${ }^{4}$ & & 0.09 & 0.53 & & & & & & \\
\hline Current asthmatics & 430 & 2.979 & 0.606 & 1.010 & 2.979 & 3.585 & 3.592 & $<0.001$ & 1.000 \\
\hline$p$-value ${ }^{4}$ & & 0.09 & 0.03 & & & & & & \\
\hline \multicolumn{10}{|l|}{ Whites } \\
\hline Non-asthmatics & 5711 & 3.276 & 0.849 & 0.909 & 3.276 & 4.124 & 4.047 & 0.050 & 0.994 \\
\hline Former asthmatics & 813 & 3.334 & 0.843 & 0.904 & 3.334 & 4.177 & 4.096 & 0.042 & 0.996 \\
\hline Current asthmatics & 377 & 3.108 & 0.837 & 0.875 & 3.108 & 3.945 & 3.841 & $<0.001$ & 1.000 \\
\hline$p$-value ${ }^{4}$ & & 0.43 & 0.84 & & & & & & \\
\hline \multicolumn{10}{|l|}{ Non-whites } \\
\hline Non-asthmatics & 4464 & 2.500 & 0.453 & 1.218 & 2.500 & 2.953 & 3.052 & 0.061 & 0.988 \\
\hline Former asthmatics & 626 & 2.566 & 0.784 & 0.991 & 2.566 & 3.350 & 3.343 & $<0.001$ & 1.000 \\
\hline
\end{tabular}

RMSEA, root mean squared error of approximation; CFI, comparative fit index.

${ }^{1}$ Assessed by considering smoking frequency (ranging from one to five [the number of days smoked cigarettes during the past 30 days, never to everyday]) and quantity (ranging from one to five [the number of cigarettes per day on the days smoked during the past 30 days, 0 to $\geq 40$ ]): the score of cigarette use behaviors ranged from two to 10 (the sum of smoking frequency and quantity scores).

${ }^{2}$ Current asthmatics were defined as those who had been diagnosed with asthma, and had been treated for asthma during the past 12 months. Former asthmatics were defined as those who had been diagnosed with asthma, but had not been treated for asthma during the past 12 months. Non-asthmatics were defined as those who had never been diagnosed with asthma.

${ }^{3}$ Intercepts and slopes were determined using a linear change model with the final time point (Wave IV) freely estimated. Separate models were tested for the separate asthma subgroups.

${ }^{4} p$-values were calculated from a model including asthma status as a covariate.

ma, diabetes mellitus, and cystic fibrosis $[25,26]$. Existing theories have addressed possible roles of low self-esteem, decreased peer acceptance, and increased life stressors in the engagement of risk-taking behaviors among young people with chronic illness [26]. Particularly, studies evaluating risk factors for cigarette smoking among asthmatic youth have suggested that young people with or without asthma smoke for similar reasons [12,13]. A study of 3234 students attending public high school in Memphis, Tennessee, in 1997 [12] showed that former asthmatics, but not current asthmatics, were more likely than non-asthmatics to smoke weekly. In addition, this study revealed that current asthmatics were more likely than non-asthmatics to report intentions to smoke within the next year. This study also indicated that reasons for cigarette smoking did not differ by asthma status, with the exception of non-asthmatics believing that smoking is relaxing. In a national cross-sectional study of Danish adolescents during 1996-1997 [13], asthmatic adolescents, especially asthmatic boys, were more likely than their healthy peers to start smoking because they felt pressured, and to smoke currently to stay slim, indicative of possible sex differences in the 
management of their chronic illness [25].

It is also noteworthy that some longitudinal studies have suggested a bidirectional association between asthma and cigarette smoking. Namely, cigarette smoking increases the risk of developing asthma and having asthma predicts the engagement in cigarette smoking $[27,28]$. In a longitudinal study among Dutch adolescents, Van De Ven et al. [28] assessed asthma-specific predictors of cigarette smoking and reported low medication adherence and some psychosocial factors such as coping and quality of life as smoking predictors among asthmatic adolescents. In a cohort of adults with asthma in the US, Eisner et al. [29] evaluated several factors predisposing asthmatics to initiate and quit cigarette smoking. Their study revealed that non-Hispanic white race, low educational attainment, and presence in childhood residence of an adult who smoked were associated with an increased risk of smoking initiation. Furthermore, adolescence-onset asthma, low educational attainment, early smoking initiation, and heavy cigarette use were associated with a longer interval until smoking cessation.

The strengths of this study include the use of panel data to assess changes in cigarette use behaviors over multiple time points and the evaluation of these changes using latent growth curve models. As panel data consist of a series of cross-sectional studies of the same individuals, these data allow for the examination of changing patterns over the life course. With regard to statistical methodology, latent growth curve modeling allows the investigator to test the adequacy of the hypothesized growth form [30]. Nevertheless, the findings on cigarette use behaviors among young people with asthma noted in the present study should be interpreted with caution. The limitations of this study include the use of self-reported asthma status, which was not confirmed by medical records or clinical tests, and the possibility of under-reporting on cigarette use behaviors due to the reliance on self-reports. The validity of self-reported smoking has been assessed in previous studies, suggestive of the careful use of self-reports on adolescent smoking [31]. Contextual and community factors that may have an impact on cigarette use behaviors among youth (e.g., local tobacco policies including tobacco sales policies) should be also taken into account, when interpreting these results [32]. Additionally, the arbitrarily-defined cigarette smoking score can make it hard to interpret the results of study. Nonetheless, this study, which was conducted using a nationally representative data, expands the understanding of the changing patterns of cigarette use behaviors among asthmatic youth during the transition to adulthood.

In conclusion, this study suggests that the changing patterns of cigarette use behaviors during the transition to adulthood among young people with asthma are comparable to or even more drastic than that among young people without asthma. Considering the substantial health risk of cigarette smoking, more emphasis needs be placed on effective smoking prevention and cessation programs for this vulnerable population.

\section{ACKNOWLEDGEMENTS}

Special thanks are extended to Dr. Gye-Soo Kim for giving expert advice on research methodology. This work was supported by research grants from the Catholic University of Daegu in 2012. This research uses data from Add Health, a program project directed by Kathleen Mullan Harris and designed by J. Richard Udry, Peter S. Bearman, and Kathleen Mullan Harris at the University of North Carolina at Chapel Hill, and funded by grant P01-HD31921 from the Eunice Kennedy Shriver National Institute of Child Health and Human Development, with cooperative funding from 23 other federal agencies and foundations. Special acknowledgment is due to Ronald R. Rindfuss and Barbara Entwisle for assistance in the original design. Information on how to obtain the Add Health data files is available on the Add Health website (http://www.cpc.unc.edu/addhealth). No direct support was received from grant P01-HD31921 for this analysis.

\section{CONFLICT OF INTEREST}

The author has no conflicts of interest with the material presented in this paper.

\section{REFERENCES}

1. Pearce N, Aït-Khaled N, Beasley R, Mallol J, Keil U, Mitchell E, et al. Worldwide trends in the prevalence of asthma symptoms: phase III of the International Study of Asthma and Allergies in Childhood (ISAAC). Thorax 2007;62(9):758-766.

2. Centers for Disease Control and Prevention (CDC). Asthma's impact on the nation data from the CDC National Asthma Control Program [cited 2014 Dec 4]. Available from: http://www.cdc. gov/asthma/impacts_nation/asthmafactsheet.pdf.

3. Korea Centers for Disease Control and Prevention. Reports on the Korea Youth Risk Behavior Web-based Survey, 2014. Cheongju: Korea Centers for Disease Control and Prevention; 
2014, p. 326-337 (Korean).

4. Jones SE, Merkle S, Wheeler L, Mannino DM, Crossett L. TobacCo and other drug use among high school students with asthma. J Adolesc Health 2006;39(2):291-294.

5. Precht DH, Keiding L, Madsen M. Smoking patterns among adolescents with asthma attending upper secondary schools: a community-based study. Pediatrics 2003;111(5 Pt 1):e562e568.

6. Calam R, Gregg L, Goodman R. Psychological adjustment and asthma in children and adolescents: the UK Nationwide Mental Health Survey. Psychosom Med 2005;67(1):105-110.

7. McQuaid EL, Kopel SJ, Nassau JH. Behavioral adjustment in children with asthma: a meta-analysis. J Dev Behav Pediatr 2001; 22(6):430-439.

8. Miauton L, Narring F, Michaud PA. Chronic illness, life style and emotional health in adolescence: results of a cross-sectional survey on the health of 15-20-year-olds in Switzerland. Eur J Pediatr 2003;162(10):682-689.

9. Bender BG. Risk taking, depression, adherence, and symptom control in adolescents and young adults with asthma. Am J Respir Crit Care Med 2006;173(9):953-957.

10. McLeish AC, Cougle JR, Zvolensky MJ. Asthma and cigarette smoking in a representative sample of adults. J Health Psychol 2011;16(4):643-652.

11. Thomson NC, Chaudhuri R, Livingston E. Asthma and cigarette smoking. Eur Respir J 2004;24(5):822-833.

12. Zbikowski SM, Klesges RC, Robinson LA, Alfano CM. Risk factors for smoking among adolescents with asthma. J Adolesc Health 2002;30(4):279-287.

13. Precht DH, Keiding L, Nielsen GA, Madsen M. Smoking among upper secondary pupils with asthma: reasons for their smoking behavior: a population-based study. J Adolesc Health 2006; 39(1):141-143.

14. Tercyak KP. Brief report: social risk factors predict cigarette smoking progression among adolescents with asthma. J Pediatr Psychol 2006;31(3):246-251.

15. Dowdell EB, Posner MA, Hutchinson MK. Cigarette smoking and alcohol use among adolescents and young adults with asthma. Nurs Res Pract 2011;2011:503201.

16. Cicchetti D, Cohen DJ. Developmental psychopathology. Vol. 1 , theory and method. Hoboken: Wiley; 2006, p 1-23.

17. National Longitudinal Study of Adolescent to Adult Health. Study design [cited 2014 Dec 4]. Available from: http://www. cpc.unc.edu/projects/addhealth/design.

18. Chen P, Chantala K. Guidelines for analyzing Add Health data;
2014 [cited 2014 Dec 4]. Available from: http://www.cpc.unc. edu/projects/addhealth/data/guides/wt-guidelines.pdf.

19. White HR, Pandina RJ, Chen PH. Developmental trajectories of cigarette use from early adolescence into young adulthood. Drug Alcohol Depend 2002;65(2):167-178.

20. Brown TA. Confirmatory factor analysis for applied research. 2nd ed. New York: Guilford Press; 2015, p. 67-74.

21. Caldeira KM, O'Grady KE, Garnier-Dykstra LM, Vincent KB, Pickworth WB, Arria AM. Cigarette smoking among college students: longitudinal trajectories and health outcomes. Nicotine Tob Res 2012;14(7):777-785.

22. Stapleton M, Howard-Thompson A, George C, Hoover RM, Self TH. Smoking and asthma. J Am Board Fam Med 2011;24(3): 313-322.

23. Bernat DH, Klein EG, Forster JL. Smoking initiation during young adulthood: a longitudinal study of a population-based cohort. J Adolesc Health 2012;51(5):497-502.

24. Brook DW, Brook JS, Zhang C, Whiteman M, Cohen P, Finch SJ. Developmental trajectories of cigarette smoking from adolescence to the early thirties: personality and behavioral risk factors. Nicotine Tob Res 2008;10(8):1283-1291.

25. Williams $C$. Doing health, doing gender: teenagers, diabetes and asthma. Soc Sci Med 2000;50(3):387-396.

26. Valencia LS, Cromer BA. Sexual activity and other high-risk behaviors in adolescents with chronic illness: a review. J Pediatr Adolesc Gynecol 2000;13(2):53-64.

27. Van de Ven MO, Engels RC, Kerstjens HA, Van den Eijnden RJ. Bidirectionality in the relationship between asthma and smoking in adolescents: a population-based cohort study. J Adolesc Health 2007;41(5):444-454.

28. Van De Ven MO, Engels RC, Sawyer SM. Asthma-specific predictors of smoking onset in adolescents with asthma: a longitudinal study. J Pediatr Psychol 2009;34(2):118-128.

29. Eisner MD, Yelin EH, Katz PP, Shiboski SC, Henke J, Blanc PD. Predictors of cigarette smoking and smoking cessation among adults with asthma. Am J Public Health 2000;90(8):1307-1311.

30. Duncan TE, Duncan SC, Strycker LA. An introduction to latent variable growth curve modeling: concepts, issues, and applications. 2nd ed. New York: Psychology Press; 2011, p. 1-15.

31. Wong SL, Shields M, Leatherdale S, Malaison E, Hammond D. Assessment of validity of self-reported smoking status. Health Rep 2012;23(1):47-53.

32. Lipperman-Kreda S1, Grube JW, Friend KB. Contextual and community factors associated with youth access to cigarettes through commercial sources. Tob Control 2014;23(1):39-44. 